Revue d'histoire de l'Amérique française

REVUE D.HISTOIRE DE L'AMÉRIQUE FRANÇAISE

\title{
L'acte de baptême du fils de Jamet Quartier
}

\section{R. La Roque de Roquebrune}

Volume 7, numéro 4, mars 1954

URI : https://id.erudit.org/iderudit/301626ar

DOI : https://doi.org/10.7202/301626ar

Aller au sommaire du numéro

Éditeur(s)

Institut d'histoire de l'Amérique française

ISSN

0035-2357 (imprimé)

1492-1383 (numérique)

Découvrir la revue

Citer ce document

La Roque de Roquebrune, R. (1954). L'acte de baptême du fils de Jamet Quartier. Revue d'histoire de l'Amérique française, 7(4), 571-572.

https://doi.org/10.7202/301626ar d'utilisation que vous pouvez consulter en ligne.

https://apropos.erudit.org/fr/usagers/politique-dutilisation/ 


\section{DOCUMENTS INÉDITS ${ }^{1}$}

\section{L'ACTE DE BAPTÊME DU FILS DE JAMET QUARTIER}

J'avais cru avec candeur que ce document était demeuré jusqu'ici "introuvê", ainsi que l'écrit Mlle Marie-Claire Daveluy. Mais je me permets de lui assurer ici que je n'apporte aucune vanité dans la découverte que je peux faire de documents "introuvés" et même introuvables. Car au cours de ma carrière j'en ai tant trouvé que je suis un peu blasé sur ce genre de volupté.

En tout cas, ses remarques m'ont donné le désir de me pencher de nouveau sur la page du Registre qui contient l'acte de baptême du fils de Jamet Quartier. Et j'y lis de nouveau Josseline Jansart et non Gesseline, petit compère Poullet et nullement Raoullet, par don E. et pas du tout Perdriel.

La lecture attentive des autres actes permet de découvrir facilement la signature de Dom Estienne Rouxel. L'acte de baptême de Pierre Le Juiff, qui suit immédiatement celui du fils de Jamet Quartier, est très lisiblement signé: "baptizé p. Dom Estienne Rouxel". L'acte de baptême de Guillaume Bruler, qui est le premier à droite, est signé: "baptizế par Dom Estienne Rouxel". Enfin, l'acte de baptême de la fille "à Jehan Jouyn", qui est le troisième à droite du Registre, est signé: "baptizée par Estienne Rouxel". Le mot Dom a été omis par le prêtre, lequel a écrit en gros caractères, très nets, après et sous sa signature: "O.F.M." et peut-être "O.F.M.J." si le $J$ n'est pas simplement un paraphe.

Le savant petit cours de Mlle Daveluy sur le calendrier julien n'est pas tout à fait aussi savant qu'il semblerait. Au Moyen âge et jusqu'à la réforme du calendrier, le style de Pâques et le style de la Circoncision ont été observés simultanément en France. Certaines régions observaient même le style de la Nativité. De sorte que l'année commençait soit à Pâques, soit le 1er janvier ou le 25 décembre. Il arrivait souvent que, dans la même ville, la juridiction royale, les juridictions seigneuriales, la cour ecclésiastique et la commune ne suivaient pas le même style. Beaucoup de documents en font foi.

Mais il est certain que le style de Pâques était d'usage général et que c'est celui que l'on a observé jusqu'à la réforme du calendrier. Sauf pourtant dans les domaines des Plantagenets (Anjou et Poitou) où dominait le style de la Circoncision qu'adopta également l'Angleterre.

L'ouest de la France a-t-il plus ou moins subi l'influence plantagenet à une certaine époque? Les remarques de Mlle Daveluy m'ayant ramené au

1. Voir Revue d' Histoire de l' A mérique française (sept. 1953), 293-295; (dóc. 1953), 435-439. 
Registre des baptêmes de Saint-Malo, je suis de nouveau tombé en arrêt devant les deux mots qui séparent l'acte du XXXI décembre, lequel est celui du baptême du fils de Jamet Quartier, de l'acte suivant, du VII janvier, qui est celui de Pierre Le Juiff. J'avais cru lire "Primum Anny" et même Primium Anny". Latin bizarre et qui me laissait pantois. Pantois, en effet, car il faut lire et j'ai déchiffré "Initium Anny", mots écrits en gros caractères, d'un "œil" plus important que le texte, mais d'une lecture difficile.

Me trompé-je? Il me paraît cependant que ces mots tracés entre l'acte du 31 décembre et celui du 7 janvier indiquent qu'à Saint Malo, à la fin du $\mathrm{XVe}$ siècle, on faisait commencer l'année en janvier et nullement à Pâques. A moins (je veux prévoir les objections de Mlle Daveluy, laquelle me fait grand peur, je l'avoue), à moins que ces mots n'aient été écrits en surcharge plus tard, après la réforme du calendrier.

En tout cas, je ne veux pas permettre que Mlle Daveluy croie, comme elle le dit aimablement, que je m'illusionne sur la valeur de "mon document", car je pense avoir écrit que deux pièces d'archives, publiées par H.P. Biggar, le contredisent quant à la date de naissance de Jacques Cartier.

R. La Roque de Roquebrune 